\title{
Neural correlates of an early attentional capture by positive distractor words
}

\author{
José A. Hinojosa ${ }^{1,2}$ *, Francisco Mercado ${ }^{3}$, Jacobo Albert ${ }^{1,4}$, Paloma Barjola $^{3}$, Irene Peláez ${ }^{3}$, \\ Cristina Villalba-García ${ }^{1}$ and Luis Carretié ${ }^{4}$
}

1 Instituto Pluridisciplinar, Universidad Complutense de Madrid, Madrid, Spain

${ }_{2}^{2}$ Facultad de Psicología, Universidad Complutense de Madrid, Madrid, Spain

${ }^{3}$ Facultad de Ciencias de la Salud, Universidad Rey Juan Carlos, Madrid, Spain

${ }^{4}$ Facultad de Psicología, Universidad Autónoma de Madrid, Madrid, Spain

\section{Edited by:}

Cornelia Herbert, University Clinic for

Psychiatry and Psychotherapy,

Tuebingen, Germany

Reviewed by:

Lars Kuchinke, Ruhr Universität

Bochum, Germany

Johanna Maria Kissler, University of

Bielefeld, Germany

\section{*Correspondence:}

José A. Hinojosa, Instituto

Pluridisciplinar, Universidad

Complutense de Madrid, Paseo Juan

XXIII, 1, Madrid 28040, Spain

e-mail: hinojosa@pluri.ucm.es

Exogenous or automatic attention to emotional distractors has been observed for emotional scenes and faces. In the language domain, however, automatic attention capture by emotional words has been scarcely investigated. In the current event-related potentials study we explored distractor effects elicited by positive, negative and neutral words in a concurrent but distinct target distractor paradigm. Specifically, participants performed a digit categorization task in which task-irrelevant words were flanked by numbers. The results of both temporo-spatial principal component and source location analyses revealed the existence of early distractor effects that were specifically triggered by positive words. At the scalp level, task-irrelevant positive compared to neutral and negative words elicited larger amplitudes in an anterior negative component that peaked around $120 \mathrm{~ms}$. Also, at the voxel level, positive distractor words increased activity in orbitofrontal regions compared to negative words. These results suggest that positive distractor words quickly and automatically capture attentional resources diverting them from the task where attention was voluntarily directed.

\section{Keywords: emotion, positive distractors, anterior N1, word processing, event-related potentials}

\section{INTRODUCTION}

In order to maintain coherent behavior in a continuously changing environment, attentional processes are controlled endogenously to allow for keeping goal-directed behaviors in spite of distracting events. At the same time, organisms need to be able to effectively process novel, unexpected events, that could be either advantageous or dangerous, so as to ensure appropriate responses with either approach or avoidance behavior (Egeth and Yantis, 1997; Chica etal., 2013). The mechanism that is able to detect the appearance of these new events is called exogenous attention (also referred to as bottom-up, involuntary or stimulus-driven attention). It may be described as an adaptive mechanism for the rapid detection and processing of biologically relevant events, even when individuals are engaged in a resource-consuming task (Carretié, 2014). Exogenous shifts are reflexive, with attention being automatically pulled by external stimulation. According to different theoretical views (see Yantis, 2000 for a review), exogenous attention involves several processes such as the spatial automatic orientation of processing resources toward those events that deserve further processing (Sokolov, 1963; Graham and Hackley, 1991; Corbetta and Shulman, 2002; Posner et al., 2007), or the modulation of perceptual neural mechanisms that potentiate the processing of those stimuli capturing attention (Serences and Yantis, 2007; Asplund et al., 2010).

The results of several event-related potential (ERP) studies have revealed that some components may be related to distinct mechanisms involved in exogenous attention. In this sense, an anterior N1component peaking around $100 \mathrm{~ms}$ has been associated with an attentional mechanism of the prefrontal cortex, which directs attention and generates a bias signal that either enhances or suppresses sensory representations in visual pathways (Hillyard and Anllo-Vento, 1998; Barceló et al., 2000; Di Russo et al., 2003). Perceptual potentiation seems to be reflected by modulations in posterior P1and N1 components peaking around 100 and $150 \mathrm{~ms}$, respectively, (Hillyard et al., 1998; Vogel and Luck, 2000; Di Russo et al., 2005; Natale et al., 2006). Several dorsal and ventral brain areas in the frontal and parietal cortex have been proposed to subserve attentional networks implicated in exogenous attention (see Corbetta and Shulman, 2002, and Corbetta et al., 2008 for reviews). These regions seem also to exert a modulatory control over the activity of occipital visual cortices (Kastner et al., 1998; Brefczynski and DeYoe, 1999).

Emotional stimuli are particularly relevant for an organism's survival. Indeed, enhanced shifts in attention from the target stimulus toward competing emotional as compared to neutral faces or scenes presented as distractors are consistently observed (see Carretié, 2014, and Pourtois et al., 2013, for reviews). Capture of exogenous attention by emotional distractors increases reaction times and/or errors (e.g., Schimmack and Derryberry, 2005; Hodsoll et al., 2011). Also, depending on task demands and the current stimuli used, modulations by emotional compared to neutral distractors affect relatively early and/or late ERP components, including the P1 and the N1, as well as the so-called early posterior negativity (EPN), the P2 and the Late Positive Component late positive component (LPC; e.g., digit-categorization tasks: Carretié et al., 2009; perceptual 
discrimination tasks: Doallo et al., 2006; De Cesarei et al., 2009; Pourtois et al., 2010). Finally, studies providing spatial information on brain activity have revealed the involvement of visual cortices and fronto-parietal attentional networks in the processing of task-irrelevant emotional stimuli (e.g., Vuilleumier et al., 2001; Pessoa and Ungerleider, 2004; Mitchell et al., 2007; Carretié et al., 2012).

Correlates of exogenous attentional capture by emotional taskirrelevant stimuli have been also observed in the language domain, although the mechanisms that operate for the processing of verbal distractors have been much less explored than for pictorial materials. Several studies have used experimental paradigms in which targets and emotional distractor words were not concurrent in time, such as the dot probe task (e.g., MacLeod et al., 1986), affective variants of the cue-target paradigm (e.g., Stormark et al., 1995; Amir et al., 2003), or the attentional blink paradigm (e.g., Keil and Ihssen, 2004; Arnell et al., 2007). Overall, these studies have provided important information on exogenous attention processes, which suggests that emotional verbal distractors elicited an involuntary capture of attention. However, some limitations have been noted since orienting toward and disengaging from a stimulus are processes that may be difficult to differentiate in these paradigms (Salemink et al., 2007; Cisler et al., 2009). Similar concerns have been raised about using tasks in which emotional distractors and targets engaging voluntary attention are not physically segregated. Examples of these paradigms are those exploring the emotional Stroop effect (e.g., McKenna and Sharma, 1995; Thomas et al., 2007; González-Villar et al., 2014), those using affective lexical decision tasks (Hofmann et al., 2009; Hinojosa et al., 2010b), or those where specific non-emotional aspects (e.g., letter font detection) of words have to be identified (e.g., Schacht and Sommer, 2009a; Hinojosa et al., 2014). It has been claimed that these tasks may not trigger some of the processes involved in exogenous attention, such as spatial reorienting mechanisms (Carretié, 2014). Indeed, they have been most commonly used to explore lexical or conflict-related processes rather than exogenous attention.

A different source of evidence comes from studies using concurrent but distinct target distractor paradigms (CDTD) or directed attention tasks (MacNamara et al., 2013; Carretié, 2014). In these tasks, elements on the screen to which voluntary attention must be directed to perform a task (targets) and elements that are taskirrelevant (distractors) appear at the same time but are physically segregated. The use of CDTD tasks may be a suitable tool to explore exogenous attention mechanisms since both orienting of attention and sensory enhancement processes seem to be operating in these paradigms (Carretié, 2014). To the best of our knowledge, however, only three studies have compared the processes triggered by emotional and neutral distractor words with CDTD tasks (see also Rampone et al., 2014, who did not include neutral distractor words). The results of these studies suggest that emotional words capture attention to a lesser extent than do scenes or faces (Carretié, 2014), which are in line with reports showing differences in the processing of emotional pictorial and verbal stimuli (Hinojosa et al., 2009; Schacht and Sommer, 2009b; Frühholz et al., 2011; Schlochtermeier et al., 2013). In this sense, Harris and Pashler (2004) found slowed reaction times to negative distractors only after the first presentation of task-irrelevant words using a digit categorization task. Also with this paradigm, Aquino and Arnell (2007) reported increased reaction times to sexually explicit distractors compared to neutral words, but not between threatening or school-related items and neutral words. Finally, Trauer et al. (2012) used a visual foreground perceptual task to investigate distraction effects by emotional words on steady-state visual evoked potentials (SSVEPs). Behavioral data and SSVEP amplitudes showed no differences regardless of the emotional content of distractor words, which was taken to suggest an absence of attentional modulation in early visual areas. Lexico-semantic effects in middle and late latency ERP components were also explored. The authors found enhanced amplitudes in the P2 and N400 components to negative task-irrelevant words and concluded that emotional distractor words captured lexico-semantic processing resources.

The heterogeneity of the findings suggests that more studies are needed in order to clarify how the distinct processes involved in exogenous attention modulate the processing of task-irrelevant emotional words. In this sense, compared with behavioral measures, ERPs make it possible to determine which stages are being affected by a specific experimental manipulation. Another advantage over behavioral methods is that they can provide a measure of processing stimuli even when there is no behavioral change. In the only prior ERP study, Trauer et al. (2012) focused their ERP analyses on the stage of elaborated meaning evaluation P2, N400, and LPC components- due to some limitations of the SSVEP procedures to explore early latency components. Thus, the involvement of orienting mechanisms and/or enhanced sensory processing that occur at early attentional processing stages remains still unexplored with ERPs. The present study sought to clarify the mechanisms involved in exogenous attention to verbal stimuli. To this end, emotional and neutral words were presented as distractors while participants carried out a demanding digit categorization CDTD task. We expected effects to arise in those ERP components that have been associated with the automatic orientation of processing resources and/or the modulation of perceptual neural mechanisms in prior literature, namely the P1 and the N1 (Hillyard et al., 1998; Di Russo et al., 2005). Additionally, we examined those components - the P2, the EPN, the N400, and the LPCthat have been modulated by emotional content in word processing studies with a variety of experimental paradigms including lexical decision tasks (Kanske and Kotz, 2007; Scott et al., 2009; Méndez-Bértolo et al., 2011), silent reading (Kissler et al., 2007, 2009; Herbert et al., 2008), structural decision tasks (i.e., identification of italicized letters, Schacht and Sommer, 2009a), or grammatical decision tasks (i.e., counting of nouns or adjectives, Kissler et al., 2009).

As a second goal, we explored the neural origin of exogenous attention to emotional distractor words, a question that has not been addressed in previous research. To this aim, source location analyses were performed using exact low resolution brain electromagnetic tomography (eLORETA; Pascual-Marqui, 2007). According to previous literature, activation of those brain regions underlying attentional networks and emotional processing was hypothesized, namely frontal, parietal and/or extrastriate visual cortices (Vuilleumier, 2005). 


\section{MATERIALS AND METHODS PARTICIPANTS}

Thirty undergraduate students ( 23 females and 7 males) from the Universidad Rey Juan Carlos, with an age range between 18 and $26($ mean $=18.96, \mathrm{SD}=1.92)$, participated in this experiment. Participants were native speaker of Spanish and right-handed, as assessed with the Edinburgh Handedness Inventory (Oldfield, 1971): LQ > +72. All subjects gave written informed consent and reported normal or corrected-to-normal visual acuity. The study was approved by the Ethics Committee of the Universidad Rey Juan Carlos.

\section{STIMULI AND PROCEDURE}

Three types of distractor words were presented to participants in a digit categorization task: negative, positive and neutral words. The complete set of verbal stimuli consisted of 150 Spanish nouns (50 per emotional category). These words were selected from a pilot study that comprised 720 nouns. In this study, 45 individuals (different from those participating in the current study) rated valence, arousal, and the level of concreteness of each word on a 9-point Likert scale (for a detailed description of the pilot study see Hinojosa et al., 2009). Equal numbers of negative, positive and neutral distractor words were selected according to several criteria that were contrasted with analyses of variance (ANOVAs; see Table 1): (a) negative and positive words were matched in arousal rating but both differed from neutral words; (b) negative, positive and neutral nouns differed in valence ratings; (c) all nouns had similar concreteness, word length and frequency of use (Alameda and Cuetos, 1995). Table 1 summarizes mean values in arousal, valence and concreteness for nouns, as well as mean word frequency and word length.

Participants sat in an electrically and acoustically isolated room in a comfortable chair. The stimuli were presented on a computer monitor that was positioned at eye level about $60 \mathrm{~cm}$ in front of the participant. Words were presented in lower case letters at fixation with digits in the left and the right periphery $\left(10^{\circ}\right.$ eccentricity). The size of all words ranged between 7.64 and $2.86^{\circ}$ (width) $\times 0.95^{\circ}$ (height). Only digits from 2 to 8 were used $\left(0.95^{\circ}\right.$ height). Words and digits appeared in black against a light gray background. The sequence of events in each trial is represented in Figure 1. First, a fixation cross appeared in the center of the screen and remained there for $500 \mathrm{~ms}$. This fixation cross was followed by a blank screen interval of $300 \mathrm{~ms}$ and then words flanked by the two digits were presented for $150 \mathrm{~ms}$ and were followed by a $1700 \mathrm{~ms}$ blank interval. The intertrial interval was $2650 \mathrm{~ms}$.

As indicated, participants performed a digit categorization task. They were told to press, 'as accurately and rapidly as possible,' one key of a response device if both digits were either even or odd (i.e., if they were 'concordant'), and a different key if one digit was even and the other was odd (i.e., if they were 'discordant'). In half of the trials digits were concordant whereas they were discordant in the other half. The same combination of digits was repeated across emotional conditions in order to ensure that task demands were identical in trials with negative, positive and neutral distractors. The order of presentation of the 150 trials (50 trials for each of the three emotional categories) was pseudorandomized so no more than three consecutive trials of the same emotional or numerical category appeared consecutively. Stimuli were presented in two runs of 75 stimuli with a brief resting period between them. Participants were requested to avoid blinking as much as they could. A training block of nine trials was provided at the beginning of the session to familiarize participants with the task.

\section{EEG RECORDING AND PRE-PROCESSING}

Continuous electroencephalographic (EEG) activity was recorded using an electrode cap (ElectroCap International) with 60 homogeneously distributed scalp electrodes. All electrodes were referenced to the linked mastoids. Electrooculographic (EOG) data were recorded supra- and infraorbitally (vertical EOG), as well as from the left versus right orbital rim (horizontal EOG). Electrode impedances were kept below $5 \mathrm{k} \Omega$. An online bandpass filter from 0.1 to $40 \mathrm{KHz}$ was used ( $3 \mathrm{~dB}$ points for $-6 \mathrm{~dB}$ /octave rolloff), and digitization sampling rate was set to $250 \mathrm{~Hz}$. Off-line pre-processing was performed using Brain Vision Analyzer software (Brain Products). The continuous EEG recording was divided into 1000-ms epochs for each trial, beginning $200 \mathrm{~ms}$ before stimulus onset. Baseline correction was made using the $200-\mathrm{ms}$ period prior to the onset of stimulus. Trials in which subjects responded erroneously or did not respond were eliminated. EOG-artifact removal was carried out following the procedure described by Gratton et al. (1983). A careful EEG visual inspection was then performed in which epochs with artifacts were eliminated from further analyses. This artifact and error rejection procedure led to an average admission of $86.6 \%$ positive, $90 \%$ neutral, and $91.8 \%$ negative trials. The ERP averages were categorized according to each distractor category (negative, neutral, and positive).

Table 1 | Means and SD of valence (1 highly unpleasant, 9 highly pleasant), arousal (1 highly calming, 9 highly arousing), concreteness (1 highly abstract, 9 highly concrete), frequency of use (per one million), number of syllables, and number of letters.

\begin{tabular}{|c|c|c|c|c|c|c|}
\hline & Valence & Arousal & Concreteness & Frequency & Syllables & Letters \\
\hline Negative & $2.13(0.5)$ & $7.29(0.5)$ & $6.10(1.3)$ & $80.72(108)$ & $2.88(0.8)$ & $7.08(2)$ \\
\hline Positive & $7.67(0.5)$ & $7.23(0.5)$ & $6.07(1.4)$ & $85.14(101.1)$ & $2.96(0.8)$ & $7.02(2)$ \\
\hline \multicolumn{7}{|l|}{ ANOVA } \\
\hline
\end{tabular}

d.f. $=2,98 ;$ n.s., non-significant, ${ }^{*} p<0.001$. 


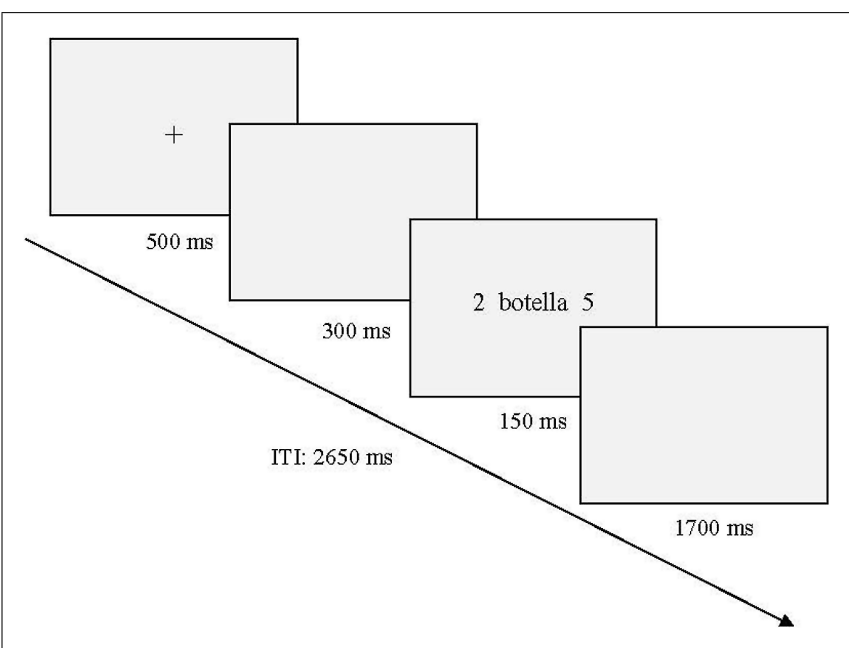

FIGURE 1 | Schematic representation of the sequence described in the main text. An example belonging to neutral words during discordant digit condition is represented ("botella" = bottle). ITI, Intertrial interval.

\section{DATA ANALYSIS \\ Behavioral analysis}

Mean reaction times (RTs) of correct responses and error rates (omissions and commissions) were analyzed. Repeated-measures ANOVAs on each measure were carried out with respect to Distractor type (three levels: negative, neutral, and positive). The Greenhouse-Geisser epsilon correction was applied when the assumption of sphericity was violated. Post hoc pairwise comparisons were two-tailed, paired-samples t-tests with Bonferroni correction for multiple comparisons. As a measure of effect size, partial $\eta$-square $\left(\eta_{p}^{2}\right)$ is reported for significant effects.

\section{ERP analysis}

Detection and quantification of ERP components was carried out through covariance-matrix-based temporal principal component analysis (tPCA). All analyses were performed using IBM SPSS v20. The main advantage of tPCA over traditional procedures based on visual inspection of recordings and on 'temporal windows of interest' is that it presents each ERP component separately and with its 'clean' shape, extracting and quantifying it free of the influences of adjacent or subjacent components (Chapman and McCrary, 1995; Dien and Frishkoff, 2005). Indeed, the waveform recorded at a site on the head over a period of several $100 \mathrm{~ms}$ represents a complex superposition of different overlapping electrical potentials. Such recordings can stymie visual inspection. In brief, tPCA computes the covariance between all ERP time points, which tends to be high between those time points involved in the same component, and low between those belonging to different components. The solution is therefore a set of independent factors made up of highly covarying time points, which ideally correspond to ERP components. Temporal factor scores, the tPCA-derived parameter in which extracted temporal factors (TFs) may be quantified, is linearly related to amplitude. In the present study, the decision on the number of components to select was based on the scree test (Cattell, 1966). Extracted components were submitted to Promax rotation, as recommended (Dien, 2010, 2012).
Given that signal overlapping may occur also at the space domain, we performed subsequent spatial PCAs on every temporal factor. At any given time point, several neural processes (and hence, several electrical signals) may concur, and the recording at any scalp location at that moment is the electrical balance of these different neural processes. While temporal PCA "separates" ERP components along time, spatial PCA (sPCA) separates ERP components along space, each spatial factor ideally reflecting one of the concurrent neural processes underlying each temporal factor. Additionally, sPCA provides a reliable division of scalp into different recording regions, an advisable strategy prior to statistical contrasts, since ERP components frequently behave differently in some scalp areas than in others (e.g., they present opposite polarity or react differently to experimental manipulations). This method of analysis is reference-independent since the configuration of the scalp topography is independent of the reference electrode position (Pourtois et al., 2008). Basically, each region or spatial factor is formed with the scalp points where recordings tend to covary. As a result, the shape of the sPCAconfigured regions is functionally based, and scarcely resembles the shape of the geometrically configured regions defined by traditional procedures. Moreover, each spatial factor can be quantified through the spatial factor score, a single parameter that reflects the amplitude of the whole spatial factor. Also in this case, the decision on the number of factors to select was based on the scree test, and extracted factors were submitted to Promax rotation.

Finally, repeated-measures ANOVAs on temporospatial factor scores were carried out with respect to Distractor type (three levels: negative, neutral, and positive). The Greenhouse-Geisser epsilon correction was applied when the assumption of sphericity was violated, and post hoc pairwise comparisons were two-tailed, paired-samples $t$-tests with Bonferroni correction for multiple comparisons. Effect sizes were also reported using the partial $\eta$-square $\left(\eta_{p}^{2}\right)$ method.

\section{Source localization analysis}

In order to three-dimensionally locate the cortical regions that were sensitive to the experimental effects observed at the scalp level, exact low-resolution brain electromagnetic tomography (eLORETA; Pascual-Marqui, 2007; Pascual-Marqui et al., 2011) was applied to relevant temporal factor scores. eLORETA is a $3 \mathrm{D}$, discrete linear solution for the EEG inverse problem, which provides inverse solutions that are reference-independent (Pascual-Marqui et al., 2011; Michel and Murray, 2012). Although, in general, solutions provided by EEG-based source-location algorithms should be interpreted with caution due to their potential error margins, LORETA solutions have shown significant correspondence with those provided by hemodynamic procedures in the same tasks (Dierks et al., 2000; Vitacco et al., 2002; Mulert et al., 2004). Moreover, the use of tPCA-derived factor scores instead of direct voltages (which leads to more accurate source-localization analyses: Dien et al., 2003, 2004; Carretié et al., 2004), contribute to reducing this error margin. In its current version, eLORETA computes the current density at each of 6239 voxels mainly located in the cortical gray matter of the digitized Montreal Neurological Institute (MNI) standard brain. 
Specifically, three-dimensional current-density estimates for relevant temporal factor scores were computed for each participant and each experimental condition. Subsequently, the voxel-based whole-brain eLORETA-images (6239 voxels) were compared between conditions using the non-parametric mapping (SnPM) tool, as implemented in the sLORETA/eLORETA software package. As explained by Nichols and Holmes (2002), the non-parametric methodology inherently avoids multiple comparison-derived problems and does not require any assumption of normality. Voxels that showed significant differences between conditions (log-F-ratio statistic, two-tailed corrected $p<0.05)$ were located in anatomical regions and Brodmann areas (BAs).

\section{RESULTS BEHAVIORAL RESULTS}

Average values for RTs, omission and commission error rates to each emotional word category are shown in the Table 2 . Three repeated-measures ANOVAs were conducted on RTs, omission and commission error rates including Distractor type as a factor Although RTs for positive distractor trials were slower than for the rest of trials, statistical analyses did not reach significance $[F(2,58)=0.883, p=0.372]$. Also, no significant results were found for error rates $[F(2,58)=1.715, p=0.191$, for omissions, and $F(2,58)=1.359, p=0.265$ for commissions].

\section{ERP RESULTS}

Figure 2 shows a selection of grand averages once the baseline value (prestimulus recording) was subtracted from each ERP. As described later, experimental effects were observed at around $120 \mathrm{~ms}$ (N1) over anterior electrode positions (see F1 and F2 locations). Figure 3 represents the topographic distribution of this effect.

As a consequence of the application of the tPCA, several TFs were extracted from the ERPs (see Figure 4). Factor peak-latency and topography characteristics revealed TF8 as the component being associated with both posterior $\mathrm{P} 1$ and anterior $\mathrm{N} 1$, which typically overlap in time (Di Russo et al., 2003). Indeed, tPCA revealed that the two components were evoked at the same latency (peaking at $120 \mathrm{~ms}$ ). However, differential characteristics of the posterior P1and the anterior N1 were patent both at the polarity and the scalp topography (as described later, see also Figure 3). Furthermore, TF7 (peaking at $140 \mathrm{~ms}$ ), TF5 (peaking at $192 \mathrm{~ms}$ ), TF6 (peaking at $270 \mathrm{~ms}$ ), and TF2 (peaking at $380 \mathrm{~ms}$ ) were related to posterior N1, P2, EPN, and N400 components, respectively. Finally, the LPC was decomposed in two centroparietal factors: TF9, peaking at $525 \mathrm{~ms}$, and TF1, peaking at $730 \mathrm{~ms}$.
As can be observed in Table 3, the sPCA decomposed TF8 in one anteriorly distributed factor (corresponding to the anterior N1) and two factors with posterior distributions (corresponding to the P1). Also, sPCA extracted three spatial factors for each of the remaining TFs. Therefore, the temporospatial PCA yielded a total of 24 factor combinations (three spatial factors extracted for each of 8 TFs).

Repeated-measures ANOVAs on these temporospatial factors with respect to Distractor type (three levels: negative, neutral, and positive) were carried out as previously described. Table 3 provides the statistical details of these analyses. As can be appreciated, the effect of Distractor type was only significant for the anterior N1. Post hoc tests with Bonferroni correction for multiple comparisons showed enhanced anterior N1 amplitudes for positive compared to neutral and negative distractor words ( $p s<0.05$ ). The anterior N1 amplitude did not differ between neutral and negative distractor words $(p=1)$. As Table 3 shows, no significant effects were found on other ERP components.

\section{SOURCE LOCALIZATION RESULTS}

The last analytic step consisted of three-dimensionally localizing the cortical regions that were responsible for the differences observed in the anterior N1. To achieve this, N1 temporal factor scores of each subject, electrode, and condition were submitted to eLORETA. Then, the voxel-based whole brain eLORETA-images (6239 voxels) were compared between conditions using the SnPM approach. N1-related activation in response to positive distractor words was associated with enhanced activity compared to negative distractor words in several voxels. As illustrated in Figure 5, these voxels were located in the orbitofrontal cortex (OFC; peak MNI coordinates: $X=45, Y=55, Z=-5$; BAs 11/10/47). Activation differences between positive and neutral distractor words did not reach significance. Consistent with results from scalp ERPs, no activation differences were found between neutral and negative distractor words in any voxel.

\section{DISCUSSION}

In the current study we investigated the processing of emotional distractor words while participants performed a digit categorization task. In line with previous studies using CDTD tasks, we did not observe any sign of attentional capture by emotional distractor words in behavioral measures. In this direction, Trauer et al. (2012) failed to report behavioral indices that evidenced the interference of emotional word content with a perceptual foreground task. Weak effects were found in other studies. In particular, delayed reaction times for emotional with respect to neutral distractor words have been reported only after the first

Table 2 | Means and SD (in parenthesis) of reaction times (RTs) and errors rates (commission/omission) to each word category (positive, negative, and neutral).

\begin{tabular}{|c|c|c|c|}
\hline & Positive words & Negative words & Neutral words \\
\hline RTs (ms) & $822.72(30.11)$ & $795.79(40.72)$ & $799.40(42.72)$ \\
\hline Error rates (commission) & $0.051(0.031)$ & $0.038(0.030)$ & $0.050(0.041)$ \\
\hline Error rates (ommission) & $0.071(0.095)$ & $0.058(0.084)$ & $0.070(0.085)$ \\
\hline
\end{tabular}



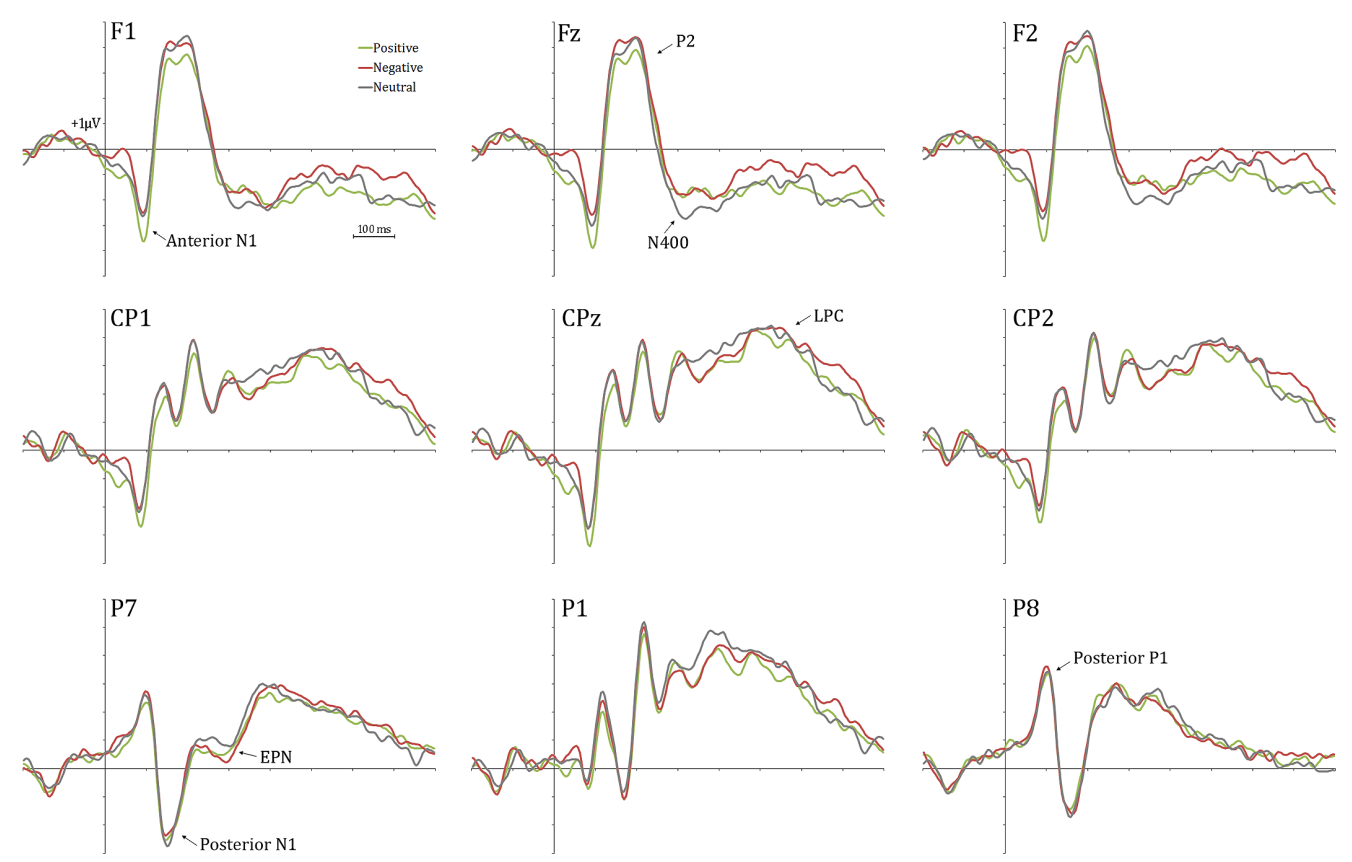

FIGURE 2 | Grand averages at a selection of electrodes. Experimental effects are clearly visible at frontal electrode sites (anterior N1).

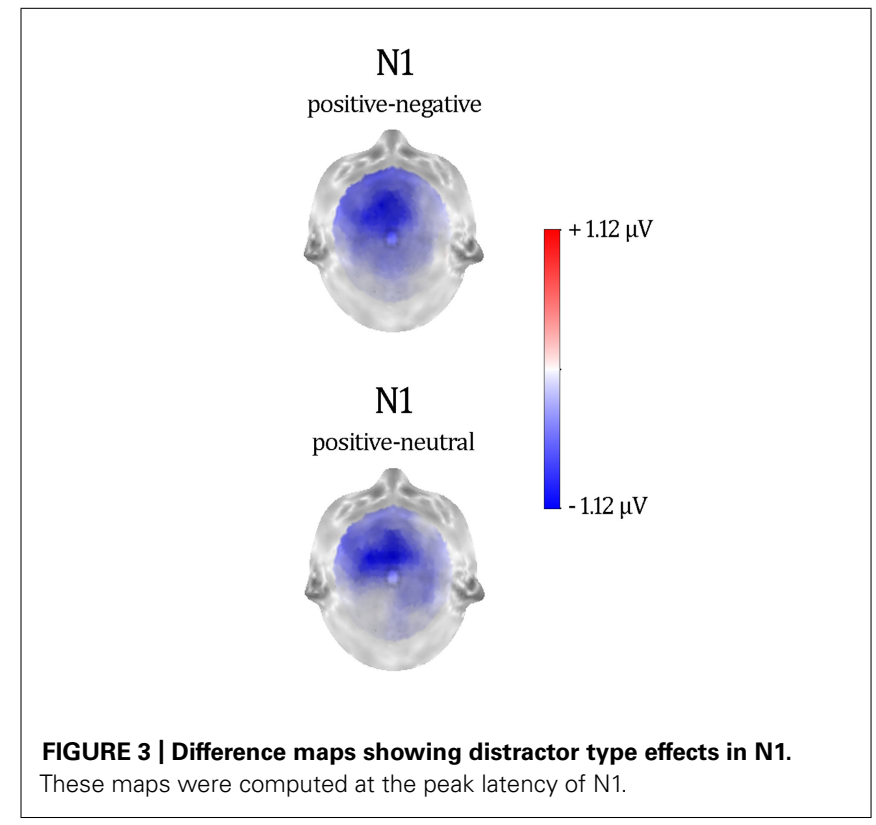

occurrence of a negative word (Harris and Pashler, 2004), or for sexually explicit words (Aquino and Arnell, 2007). Since behavioral correlates of attentional capture by task-irrelevant emotional pictures and faces are usually observed (e.g., Vuilleumier et al., 2001; MacNamara and Hajcak, 2009; Calvo and Nummenmaa, 2011; Carretié et al., 2013b; but see Holmes et al., 2006; Carretié et al., 2013a), our data fits well with the idea that word distractors may be able to interrupt ongoing processing to a lesser extent than pictorial distractors (Carretié, 2014). Nonetheless, it should be remarked that behavioral measures are the final single output of a large set of neural processes that may not be always convergent. Notably, one advantage of using ERPs is that the components can be examined in the absence of an overt behavioral response (Luck, 2005). Indeed, current results corroborate the greatest sensitivity of ERPs to the effects of certain experimental manipulations. In this respect, neural results clearly showed that the emotional content of the distractor words modulated processing-resources devoted to a primary ongoing task, as suggested both by scalp and source-location data. In particular, positive distractor nouns compared to both neutral and negative distractor words were associated with enhanced amplitudes in an anteriorly distributed negative component peaking around $120 \mathrm{~ms}$. Activity in the OFC was identified as the neural origin of this scalp-recorded component. Latency, amplitude and source-location analyses suggest that this component would be associated with attentional capture by positive distractor words. These results will be discussed in detail bellow.

As indicated in the Results section, a wave peaking around $120 \mathrm{~ms}$ after trial presentation was subdivided into two components by spatial principal component analyses. A posterior P1 deflection showed no amplitude differences between neutral and emotional distractors. Interestingly, however, positive distractor words elicited larger anterior N1 amplitudes than both negative and neutral task-irrelevant words. Similar modulations in a frontal N1 component for emotional task-irrelevant pictures have been recently found when participants' attention was engaged in a counting task (Zhang et al., 2014). Prior studies linked this component to involuntary orientation of attention to relevant stimuli (Luck et al., 1993; Di Russo et al., 2003). Specifically, it has been suggested that the anterior N1 may reflect a prefrontal attentional 


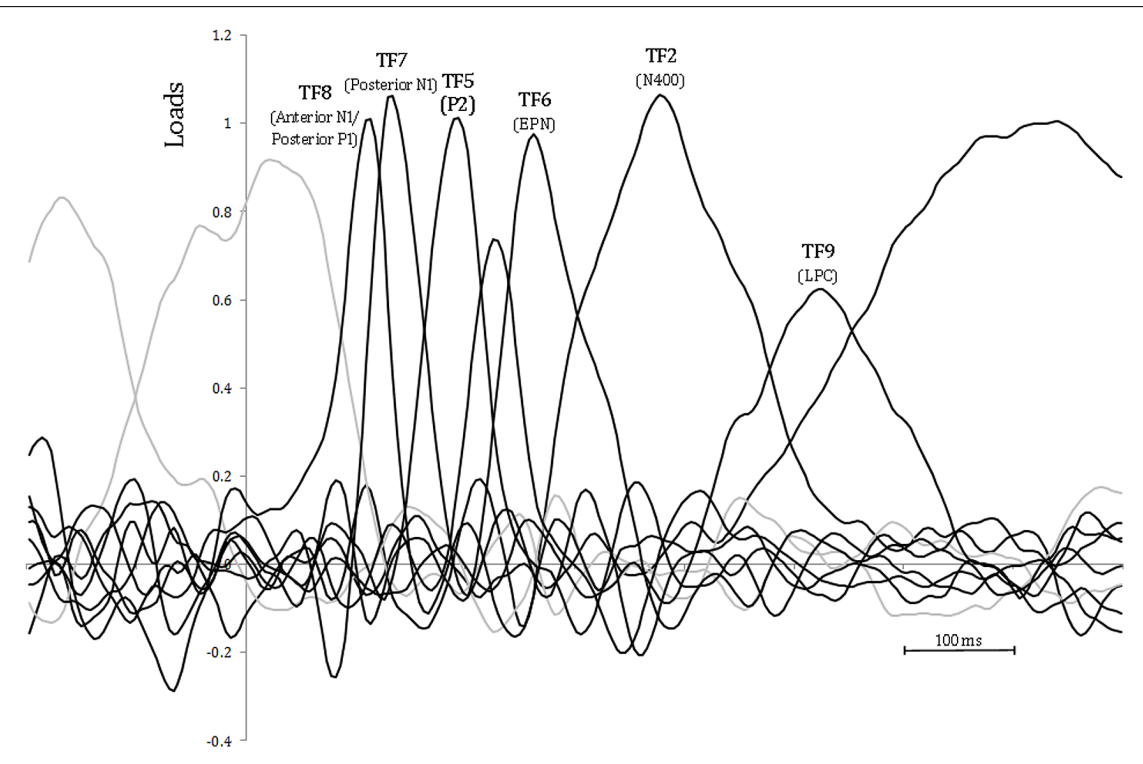

FIGURE 4 | Temporal principal component analysis (tPCA): factor loadings after Promax rotation. Peak-latency of relevant factors is shown.

Table 3 | Description and statistical results for the factors extracted by temporospatial principal component analysis.

\begin{tabular}{|c|c|c|c|c|}
\hline Temporal factor & Peak (ms) & Spatial factor & Scalp distribution & ANOVAs (Distractor type, d.f. $=2,58$ ) \\
\hline \multirow[t]{2}{*}{ TF8 (anterior N1/posterior P1) } & 110 & SF1 & Frontocentral & $F=5.04, p=0.01, \eta_{p}^{2}=0.15$ \\
\hline & & SF3 & Occipitoparietal & $F=0.15, p=0.8$ \\
\hline FT7 (posterior N1) & & SF3 & Parietooccipital (left) & $F=0.52, p=0.6$ \\
\hline \multirow[t]{2}{*}{ FT5 (P2) } & 190 & SF1 & Frontal & $F=1.04, p=0.4$ \\
\hline & & SF2 & Parietooccipital & $F=0.1, p=0.9$ \\
\hline \multirow{2}{*}{ FT6 (EPN) } & & SF2 & Parietooccipital & $F=0.85, p=0.4$ \\
\hline & & SF3 & Temporoparietal & $F=1.6, p=0.2$ \\
\hline \multirow[t]{3}{*}{ FT2 (N400) } & 380 & SF1 & Frontal & $F=1.59, p=0.2$ \\
\hline & & SF2 & Occpitoparietal & $F=1.55, p=0.2$ \\
\hline & & SF3 & Centroparietal & $F=0.78, p=0.4$ \\
\hline \multirow[t]{2}{*}{ FT9 (LPC) } & 520 & SF1 & Frontal & $F=2.26, p=0.1$ \\
\hline & & SF2 & Centroparietal & $F=0.93, p=0.4$ \\
\hline
\end{tabular}

TF, temporal factor; SF, spatial factor; d.f., degrees of freedom. 

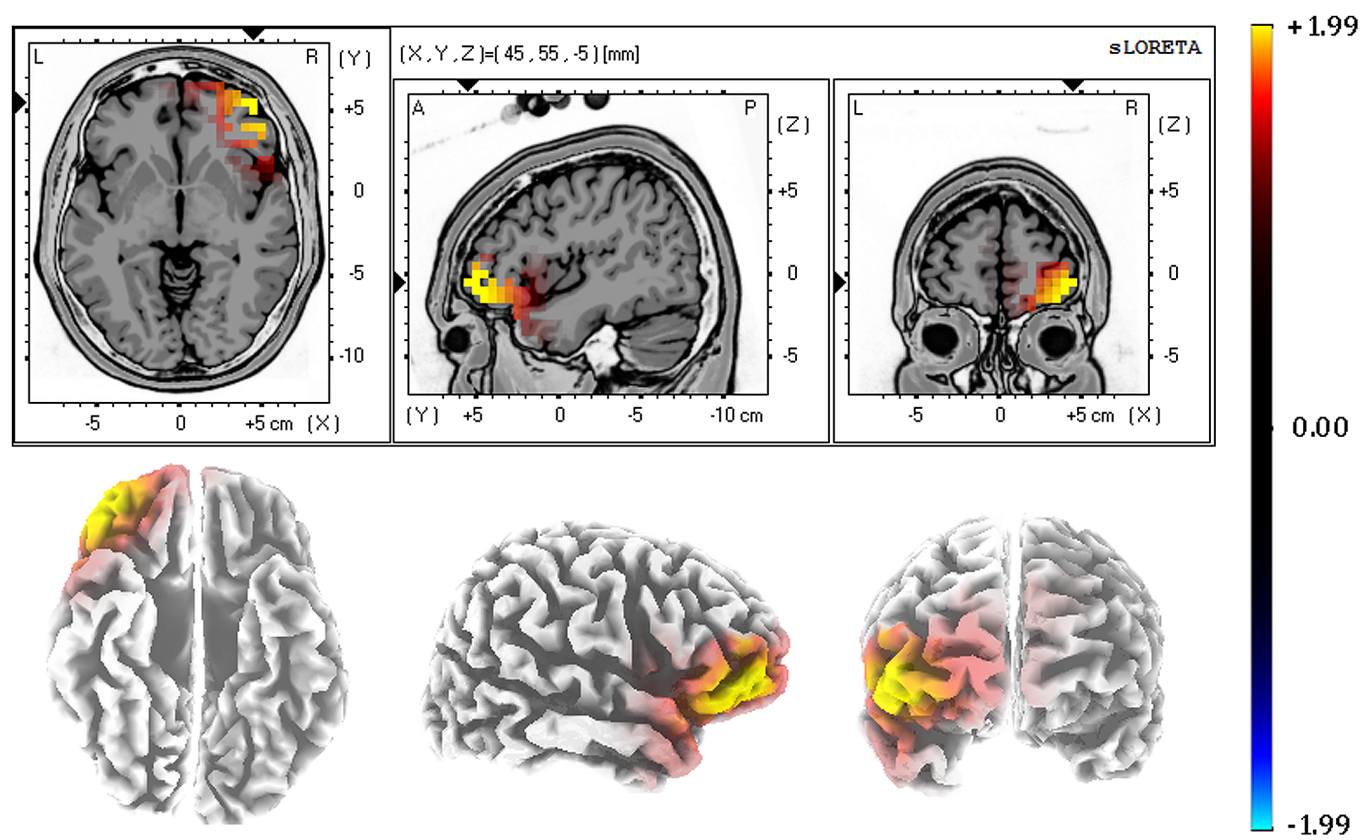

FIGURE 5 | Source localization results (eLORETA): increased N1-related activation to positive in comparison to neutral distractor words was observed in the orbitofrontal cortex. Color bar represents voxel log-F ratio values. The threshold for corrected $p<0.05$ was therefore 1.99. The strong yellow color indicates those voxels showing significant differences between conditions. mechanism that regulates sensory processing in visual cortices (Barceló et al., 2000; Pérez-Edgar and Fox, 2003).

The neural origin of our anterior $\mathrm{N} 1$, which seems to be generated in the OFC (BAs 11/10/47), argues in favor of the involvement of this region in attentional capture by positive distractor words. The OFC has been critically implicated in both the modulation of emotion and attentional control (Vuilleumier, 2005; Domínguez-Borrás and Vuilleumier, 2013). Neuroanatomical studies indicate that the OFC is reciprocally connected with the amygdala and extensive areas of prefrontal, motor and sensory cortices (Pandya and Yeterian, 1996; Cavada et al., 2000; Rolls, 2000). Specifically, it has been suggested that early activation of the OFC would modulate sensory cortices via direct feedback or indirect projections to attention and object-recognition systems in prefrontal, parietal and temporal cortices (Amaral et al., 2003; Vuilleumier, 2005). In particular, Bar et al. (2006) reported that object recognition elicited activity in the OFC around $130 \mathrm{~ms}$ and $50 \mathrm{~ms}$ before it developed in recognition-related fusiform regions. Also, activations to emotional cues in this prefrontal region have been reported around $120 \mathrm{~ms}$, using intracranial (Kawasaki et al., 2001) and scalp recordings (Pourtois et al., 2004). In line with these findings, a recent proposal postulates that the medial part of the OFC is involved in the generation of affective predictions that initiate appropriate reactions to visual information, whereas the lateral regions of the OFC seems to be implicated in computing and sending predictions about the identity of visual stimuli to the visual system (Chaumon et al., 2014). Interestingly, enhanced activity in the OFC while exogenous attention is directed to task-irrelevant emotional pictures and faces has been previously reported (Vuilleumier et al., 2001; Bishop et al., 2004; Zhang et al.,
2014). Thus, our current finding provides additional evidence supporting the implication of the OFC in exogenous attention to emotional verbal distractors, which may be triggered in part by the activation of predictive mechanism involving the processing of affective and identity-related information.

The selective enhancement of detection sensitivity to positive distractor words deserves further consideration. This finding agrees with the results of a growing body of research indicating that the OFC is a key structure in the neural circuitry of positive emotions and the processing of reward (Rolls, 2000; Burgdorf and Panksepp, 2006). In this direction, activation of the OFC has been found when mothers viewed pictures of their own compared to unfamiliar children (Nitschke et al., 2004), when participants received financial reward in a gambling task (Elliott et al., 2000), or when pleasant taste stimuli were delivered to participants (O'Doherty et al., 2001). Also, patients with OFC lesions responded faster to targets subsequent to positive distractors in a lateralized visual discrimination task (Hartikainen et al., 2012). Crucially, the results of an fMRI study by Lewis et al. (2007) showed a selective role of the OFC in the processing of valence during word processing. Thus, our data suggest activation in OFC seems to underlay selective attention to positive word distractors in CDTD tasks. Furthermore, the present results can be interpreted in terms of the positivity offset. This represents a tendency from the positive motivational system to respond more than the negative emotional system to comparably low levels of evaluative input, which seems to be the case of the processing of word distractors (Cacioppo et al., 1997; Ito and Cacioppo, 2005). Indeed, there is recent evidence indicating that as early as in the $80-120 \mathrm{~ms}$ time interval, the processing of positive and negative words implicates neural activity in 
different networks. Specifically, the processing of positive words was associated with activations in language and attention-related regions in left temporal, frontal and visual association cortices, whereas negative words activated the anterior cingulate cortex (Keuper et al., 2013). These effects were interpreted in terms of an "emotional tagging" of word forms associated to different processing strategies developed during language acquisition. These strategies include enhanced lexical processing of positive words and a fast language-independent alert response to negative words (Keuper et al., 2013). In agreement with this view, several studies reported valence-dependent effects at different processing stages that show facilitated lexical processing for positive words with both behavioral and ERPs measures (Kissler and Koessler, 2011; Kuchinke and Lux, 2012; Kissler and Herbert, 2013). This processing advantage has been linked to the orbitofrontal reward system (Kuchinke and Lux, 2012).

Resembling current findings, increased attentional capture by positive distractor compared to negative and neutral taskirrelevant words has been observed in a prior study with a similar digit categorization task (Aquino and Arnell, 2007), whereas effects for negative distractor words have been reported when participants carried out a perceptual primary task (Trauer et al., 2012). Following the proposal made by Keuper et al. (2013), it may be speculated that processing requirements imposed by the primary task may determine valence-dependent effects elicited by distractor words. In this sense, the processing of positive distractor words would be more evident in tasks demanding conceptual analysis to some extend (as in the current and in Aquino and Arnell's studies), given the greater implication of lexico-semantic processing in digit categorization tasks (see below). In contrast, activity associated with the processing of negative distractor words would be preferentially observed with primary tasks that do not require conceptual processing (e.g., the perceptual task used by Trauer et al., 2012) since the processing of negative content in words seems to rely in language-independent mechanisms according to the proposal by Keuper et al. (2013).

On another level, our results complement prior findings with CDTD tasks in several aspects. They suggest that ERP modulations triggered by task-irrelevant emotional words may emerge at different processing stages. On the one hand, in convergence with the results by Trauer et al. (2012) with a SSVEP paradigm we did not observed that emotional compared to neutral distractor words enhanced sensory processing in visual areas. This claim seems to be supported by the lack of amplitude differences in the posterior $\mathrm{P} 1$, which is mainly elicited in visual cortices (Di Russo et al., 2003, 2005). On the other hand, we only found modulations at early processing stages, which disagree with effects during meaning derivation - in P2 and N400 components- reported in Trauer et al.'s (2012) study. Tentatively, these discrepant results may be again related to the functionally different processes involved in the primary task in both studies (see above). In the experiment by Trauer et al. (2012), participants attended an array of squares in order to detect brief coherent movements in one direction, a task that mainly implies early perceptual processing. In contrast, we used a digit categorization task that relies on numerical skills that require more elaborated conceptual knowledge at the stage of meaning evaluation (Delazer, 2003). Thus, it could be speculated that the emotional content of word distractors interrupted ongoing task performance by capturing those processing resources that were involved to a lesser extent in the processing of target stimuli. The foreground task in our experiment may also account for the lack of effects in other components such as the EPN or the LPC. In this direction, although similar EPN modulations were found in tasks placing different processing demands, such as structural analysis or lexico-semantic processing (e.g., Kissler et al., 2009; Schacht and Sommer, 2009b), there is some evidence indicating that the EPN is more likely to be elicited when emotional words are deeply processed (e.g., Hinojosa et al., 2010b; Rellecke et al., 2011; Bayer et al., 2012). Similarly, task-effects have been found to modulate the amplitude of LPC (e.g., Fischler and Bradley, 2006; Schacht and Sommer, 2009b). Therefore, emotional modulations in these components seem to be more evident as the level of attention to the valence increases, although this idea requires further confirmation. Nonetheless, the results of a recent metaanalysis (Carretié, 2014) emphasized the nature of the primary task, as well as the characteristics of the distractors and individual differences, as a modulatory factor mediating attentional capture by emotional task-irrelevant stimuli (see also Mogg and Bradley, 1998).

The anterior N1 effects indicate that the processing of positive content in distractor words may operate at very early stages of the processing, as proposed by automatic vigilance models (Pratto and John, 1991) or the affective-primacy hypothesis (Zajonc, 1980; Delaney-Busch and Kuperberg, 2013), at least when the primary task implicates conceptual processing to some extent. However, the early latency of our effects raises the question about the mechanism underlying such a fast activation of emotional meaning from written words. Current findings suggest that some of the processes involved in word recognition become evident around $100 \mathrm{~ms}$ (Hauk et al., 2006). Indeed, ERP evidence has been reported suggesting a rapid access to the affective content of words as early as $80 \mathrm{~ms}$ using the semantic differential technique (Skrandies, 1998). Also, the finding of specific ERP effects for positive words between 100 and $150 \mathrm{~ms}$ with lexical decision (Bayer etal., 2012) or picture naming tasks (Hinojosa et al., 2010a) suggests that the analyses of emotional meaning has already started at $100 \mathrm{~ms}$ after word onset. An alternative explanation, however, might be outlined based on the proposal made by Bayer et al. (2012; see also Kissler et al., 2009, for similar arguments). These authors suggested that instead of fast semantic processing, non-linguistic mechanisms may contribute to early emotion effects in words. They argued that early emotional responses to words may originate from associative learning that does not depend on the semantic system given the results of previous studies that reported very early ERP modulations for non-linguistic stimuli associated with threat related pictures (Stolarova et al., 2006) and reward (Schacht et al., 2012). Additional support for this view, with verbal stimuli, comes from recent evidence showing that the activity elicited by emotionally and neutrally conditioned pseudowords differed in a negative component between 80 and $120 \mathrm{~ms}$ (Fritsch and Kuchinke, 2013). Interestingly, the OFC seems to be critically involved in rapid stimulus-reinforcement association learning for positive reinforcers (Rolls, 2000; Gottfried et al., 2003). This leaves 
open the possibility that associative learning mechanisms that are non-linguistic in nature underlie anterior N1 effects to positive distractor words.

The current study has several potential limitations. In this sense, the absence of jitter between the fixation cross and the stimulus onset may have increased early attentional processes as a result of the expectation generated when the cross appeared in the screen. Also, the presentation of the blank screen following rather short stimulus durations (150 ms) may have interfered, and thus interrupted, subsequent stimulus, and attentional processing. Future research can address these issues by randomly varying the time between the fixation cross and the stimulus and by directly comparing the processing of stimulus with different presentation durations. Finally, although the main focus of the current study was on early latency components (N1 and P1), the relatively high number of temporo-spatial factors that we explored may have increased the probability of finding significant effects.

In sum, several conclusions can be derived from current results. First, complementing previous findings with pictorial stimuli in CDTD tasks, our data show that salient but task-irrelevant words disrupt processes involved in a primary digit categorization task. Second, positive distractor words are able to engage automatic attentional resources at early stages of the processing, as reflected by modulations in an anterior N1 component. Third, activation of the OFC underlies exogenous attentional mechanisms devoted to the processing of task-irrelevant emotional words. Finally, the fact that attentional capture was selectively triggered by positive words emphasizes the involvement of this brain structure in the processing of positive emotion.

\section{AUTHOR CONTRIBUTIONS}

Conception and design of the work: José A. Hinojosa and Luis Carretié. Acquisition, analysis, or interpretation of data for the work: José A. Hinojosa, Francisco Mercado, Jacobo Albert, Paloma Barjola, Irene Peláez, Cristina Villalba-García and Luis Carretié. Drafting the work or revising it critically for important intellectual content: José A. Hinojosa, Francisco Mercado, Jacobo Albert, Paloma Barjola, Irene Peláez, Cristina Villalba-García and Luis Carretié. Final approval of the version to be published: José A. Hinojosa, Francisco Mercado, Jacobo Albert, Paloma Barjola, Irene Peláez, Cristina Villalba-García and Luis Carretié. Agreement to be accountable for all aspects of the work in ensuring that questions related to the accuracy or integrity of any part of the work are appropriately investigated and resolved: José A. Hinojosa, Francisco Mercado, Jacobo Albert, Paloma Barjola, Irene Peláez, Cristina Villalba-García and Luis Carretié.

\section{ACKOWLEDGMENTS}

This work was supported by grants PSI2012-37535 and PSI201126314 from the Ministerio de Economía y Competitividad (MINECO) of Spain, and grant PI13/01759 from the Institute of Health Carlos III (ISCIII) of Spain.

\section{REFERENCES}

Alameda, J. R., and Cuetos, F. (1995). Diccionario de Frecuencias de Las Unidades Lingüísticas Del Castellano. Oviedo: Universidad de Oviedo.

Amaral, D. G., Bauman, M. D., Capitanio, J. P., Lavenex, P., Mason, W. A., MauldinJourdain, M. L., et al. (2003). The amygdala: is i tan essential component of the neural network for social cognition?. Neuropsychologia 41, 517-522. doi: 10.1016/S0028-3932(02)00310-X

Amir, N., Elias, J., Klumpp, H., and Przeworski, A. (2003). Attentional bias to threat in social phobia: facilitated processing of threat or difficulty disengaging attention from threat?. Behav. Res. Ther. 41, 1325-1335. doi: 10.1016/S00057967(03)00039-1

Aquino, J. M., and Arnell, K. M. (2007). Attention and the processing of emotional words: dissociating effects of arousal. Psychon. Bull. Rev. 14, 430-435. doi: 10.3758/BF03194084

Arnell, K. M., Killman, K. V., and Fijavz, D. (2007). Blinded by emotion: target misses follow attention capture by arousing distractors in RSVP. Emotion 7, 465-477. doi: 10.1037/1528-3542.7.3.465

Asplund, C. L., Todd, J. J., Snyder, A. P., and Marois, R. (2010). A central role for the lateral prefrontal cortex in goal-directed and stimulus-driven attention. Nat. Neurosci. 13, 507-512. doi: 10.1038/nn.2509

Bar, M., Kassam, K. S., Ghuman, A. S., Boshyan, J., Schmid, A. M., Dale, A. M., et al. (2006). Top-down facilitation of visual recognition. Proc. Nat. Acad. Sci. U.S.A. 103, 449-454. doi: 10.1073/pnas.0507062103

Barceló, F., Suwazono, S., and Knight, R. T. (2000). Prefrontal modulation of visual processing in humans. Nat. Neurosci. 3, 399-403. doi: 10.1038/73975

Bayer, M., Sommer, W., and Schacht, A. (2012). P1 and beyond: functional separation of multiple emotion effects in word recognition. Psychophysiology 49, 959-969. doi: 10.1111/j.1469-8986.2012.01381.x

Bishop, S., Duncan, J., Brett, M., and Lawrence, A. D. (2004). Prefrontal function and anxiety: controlling attention to threat-related stimuli. Nat. Neurosci. 7, 184-188. doi: $10.1038 / \mathrm{nn} 1173$

Brefczynski, J. A., and DeYoe, E. A. (1999). A physiological correlate of the 'spotlight' of visual attention. Nat. Neurosci. 2, 370-374. doi: 10.1038/7280

Burgdorf, J., and Panksepp, J. (2006). The neurobiology of positive emotions. Neurosci. Biobehav. Rev. 30, 173-187. doi: 10.1016/j.neubiorev.2005.06.001

Cacioppo, J. T., Gardner, W. L., and Berntson, G. G. (1997). Beyond bipolar conceptualizations and measures: the case of attitudes and evaluative space. Pers. Soc. Psychol. Rev. 1, 3-25. doi: 10.1207/s15327957pspr0101_2

Calvo, M. G., and Nummenmaa, L. (2011). Time course of discrimination between emotional facial expressions: the role of visual saliency. Vision Res. 51, 1751-1759. doi: 10.1016/j.visres.2011.06.001

Carretié, L. (2014). Exogenous (automatic) attention to emotional stimuli: a review. Cogn. Affect. Behav. Neurosci. 14, 1228-1258. doi: 10.3758/s13415-0140270-2

Carretié, L., Hinojosa, J. A., López-Martín, S., Albert, J., Tapia, M., and Pozo, M. A. (2009). Danger is worse when it moves: neural and behavioral indices of enhanced attentional capture by dynamic threatening stimuli. Neuropsychologia 47, 364-369. doi: 10.1016/j.neuropsychologia.2008.09.007

Carretié, L., Kessel, D., Carboni, A., López-Martín, S., Albert, J., Tapia, M., et al. (2013a). Exogenous attention to facial vs. non-facial emotional visual stimuli. Soc. Cogn. Affect. Neurosci. 8, 764-773. doi: 10.1093/scan/nss068

Carretié, L., Albert, J., López-Martín, S., Hoyos, S., Kessel, D., Tapia, M., et al. (2013b). Differential neural mechanisms underlaying exogenous attention to peripheral and central distracters. Neuropsychologia 51, 1838-1847. doi: 10.1016/j.neuropsychologia.2013.06.021

Carretié, L., Ríos, M., Periáñez, J. A., Kessel, D., and Alvarez-Linera, J. (2012). The role of low and high spatial frequencies in exogenous attention to biologically salient stimuli. PLoS ONE 7:e37082. doi: 10.1371/journal.pone. 0037082

Carretié, L., Tapia, M., Mercado, F., Albert, J., López-Martín, S., and de la Serna, J. M. (2004). Voltage-based versus factor score-based source localization analyses of electrophysiological brain activity: a comparison. Brain Topogr. 17, 109-115. doi: 10.1007/s10548-004-1008-1

Cattell, R. B. (1966). The scree test for the number of factors. Multivar. Behav. Res. 1, 245-276. doi: 10.1207/s15327906mbr0102_10

Cavada, C., Compañy, T., Tejedor, J., Cruz-Rizzolo, R. J., and Reinoso-Suárez, F. (2000). The anatomical connections of the macaque monkey orbitofrontal cortex. A Review. Cereb. Cortex 10, 220-242. doi: 10.1093/cercor/10.3.220

Chapman, R. M., and McCrary, J. W. (1995). EP component identification and measurement by principal components analysis. Brain Cogn. 27, 288-310. doi: 10.1006/brcg.1995.1024

Chaumon, M., Kveraga, K., Barrett, L. F., and Bar, M. (2014). Visual predictions in the orbitofrontal cortex rely on associative content. Cereb. Cortex 24, 2899-2907. doi: $10.1093 /$ cercor/bht146 
Chica, A. B., Bartolomeo, P., and Lupiañez, J. (2013). Two cognitive and neural sytems for endogenous and exogenous spatial attention. Behav. Brain Res. 15, 107-123. doi: 10.1016/j.bbr.2012.09.027

Cisler, J. M., Bacon, A. K., and Williams, N. L. (2009). Phenomenological characteristics of attentional biases towards threat: a critical review. Cognit. Ther. Res. 33, 221-234. doi: 10.1007/s10608-007-9161-y

Corbetta, M., Patel, G., and Shulman, G. L. (2008). The reorienting system of the human brain: from environment to theory of mind. Neuron 58, 306-324. doi: 10.1016/j.neuron.2008.04.017

Corbetta, M., and Shulman, G. L. (2002). Control of goal-directed and stimulusdriven attention in the brain. Nat. Rev. Neurosci. 3, 201-215. doi: 10.1038/nrn755

De Cesarei, A., Codispoti, M., and Schupp, H. T. (2009). Peripheral vision and preferential emotion processing. Neuroreport 20, 1439-1443. doi: 10.1097/WNR.0b013e3283317d3e

Delaney-Busch, N., and Kuperberg, G. (2013). Friendly drug-dealers and terrifying puppies: affective primacy can attenuate the N400 effect in emotional discourse contexts. Cogn. Affect. Behav. Neurosci. 13, 473-490. doi: 10.3758/s13415-0130159-5

Delazer, M. (2003). "Neuropsychological findings on conceptual knowledge of arithmetic," in The Development of Arithmetic Concepts and Skills: Constructing Adaptive Expertise. Studies in Mathematical Thinking and Learning, eds A. J. Baroody and A. Dowker (Mahwah: Lawrence Erlbaum Associates Publishers), 385-407.

Dien, J. (2010). Evaluating two-step PCA of ERP data with geomin, infomax, oblimin, promax, and varimax rotations. Psychophysiology 47, 170-183. doi: 10.1111/j.1469-8986.2009.00885.x

Dien, J. (2012). Applying principal components analysis to event-related potentials: a tutorial. Dev. Neuropsychol. 37, 497-517. doi: 10.1080/87565641.2012.697503

Dien, J., and Frishkoff, G. (2005). "Principal components analysis of event-related potential datasets," in Event-Related Potentials: a Methods Handbook, ed. T. Handy (Cambridge: MIT Press), 189-208.

Dien, J., Spencer, K. M., and Donchin, E. (2003). Localization of the event-related potential novelty response as defined by principal components analysis. Brain Res. Cogn. Brain Res. 17, 637-650. doi: 10.1016/S0926-6410(03)00188-5

Dien, J., Spencer, K. M., and Donchin, E. (2004). Parsing the late positive complex: mental chronometry and the ERP components that inhabit the neighborhood of the P300. Psychophysiology 41, 665-678. doi: 10.1111/j.1469-8986.2004. 00193.x

Dierks, T., Jelic, V., Pascual-Marqui, R. D., Wahlund, L., Julin, P., Linden, D. E., etal. (2000). Spatial pattern of cerebral glucose metabolism (PET) correlates with localization of intracerebral EEG-generators in alzheimer's disease. Clin. Neurophysiol. 111, 1817-1824. doi: 10.1016/S1388-2457(00) 00427-2

Di Russo, F., Martínez, A., and Hillyard, S. A. (2003). Source analysis of event-related cortical activity during visuo-spatial attention. Cereb. Cortex 13, 486-499. doi: $10.1093 /$ cercor/13.5.486

Di Russo, F., Pitzalis, S., Spitoni, G., Aprile, T., Patria, F., Spinelli, D., et al. (2005). Identification of the neural sources of the pattern-reversal VEP. Neuroimage 24, 874-886. doi: 10.1016/j.neuroimage.2004.09.029

Doallo, S., Holguín, S. R., and Cadaveira, F. (2006). Attentional load affects automatic emotional processing: evidence from event-related potentials. Neuroreport 17, 1797-1801. doi: 10.1097/01.wnr.0000246325.51191.39

Domínguez-Borrás, J., and Vuilleumier, P. (2013). "Affective biases in attention and perception," in The Cambridge Handbook of Human Affective Neuroscience, eds J. Armony, and P. Vuilleumier (Cambridge: Cambridge University Press), 331-356. doi: 10.1017/CBO9780511843716.018

Egeth, H. E., and Yantis, S. (1997). Visual attention: control, representation, and time course. Annu. Rev. Psychol. 48, 269-297. doi: 10.1146/annurev.psych.48.1.269

Elliott, R., Friston, K. J., and Dolan, R. J. (2000). Dissociable neural responses in human reward system. J. Neurosci. 20, 6159-6165.

Fischler, I., and Bradley, M. (2006). Event-related potential studies of language and emotion: words, phrases, and task effects. Progr. Brain Res. 156, 185-203. doi: 10.1016/S0079-6123(06)56009-1

Fritsch, N., and Kuchinke, L. (2013). Acquired affective associations induce emotion effects in word recognition: an ERP study. Brain Lang. 124, 75-83. doi: 10.1016/j.bandl.2012.12.001

Frühholz, S., Jellinghaus, A., and Herrmann, M. (2011). Time course of implicit and explicit processing of emotional faces and emotional words. Biol. Psychol. 87, 264-274. doi: 10.1016/j.biopsycho.2011.03.008
González-Villar, A. J., Triñanes, Y., Zurrón, M., and Carrillo-de-la-Peña, M. T. (2014). Brain processing of task-relevant and task-irrelevant emotional words: an ERP study. Cogn. Affect. Behav. Neurosci. 14, 939-950. doi: 10.3758/s13415013-0247-6

Gottfried, J. A., O’Doherty, J., and Dolan, R. J. (2003). Encoding predictive reward value in human amygdala and orbitofrontal cortex. Science 301, 1104-1107. doi: $10.1126 /$ science. 1087919

Graham, F. K., and Hackley, S. A. (1991). "Passive and active attention to input," in Handbook of Cognitive Psychophysiology, eds J. R. Jennings and M. G. H. Coles (Chichester: Wiley), 251-356.

Gratton, G., Coles, M. G., and Donchin, E. (1983). A new method for off-line removal of ocular artefact. Electroencephalogr. Clin. Neurophysiol. 55, 468-484. doi: 10.1016/0013-4694(83)90135-9

Harris, C. R., and Pashler, H. (2004). Attention and the processing of emotional words and names: not so special after all. Psychol. Sci. 15, 171-178. doi: 10.1111/j.0956-7976.2004.01503005.x

Hartikainen, K. M., Ogawa, K. H., and Knight, R. T. (2012). Orbitofrontal cortex biases attention to emotional events. J. Clin. Exp. Neuropsychol. 34, 588-597. doi: $10.1080 / 13803395.2012 .666231$

Hauk, O., Davis, M. H., Ford, M., Pulvermüller, F., and Marslen-Wilson, W. D. (2006). The time course of visual word recognition as revealed by linear regression analysis of ERP data. Neuroimage 30, 1383-1400. doi: 10.1016/j.neuroimage.2005.11.048

Herbert, C., Junghofer, M., and Kissler, J. (2008). Event-related potentials to emotional adjectives during reading. Psychophysiology 45, 487-498. doi: 10.1111/j.1469-8986.2007.00638.x

Hillyard, S. A., and Anllo-Vento, L. (1998). Event-related brain potentials in the study of visual selective attention. Proc. Natl. Acad. Sci. U.S.A. 95, 781-787. doi: 10.1073/pnas.95.3.781

Hillyard, S. A., Teder-Salejarvi, W. A., and Munte, T. F. (1998). Temporal dynamics of early perceptual processing. Curr. Opin. Neurobiol. 8, 202-210. doi: 10.1016/S0959-4388(98)80141-4

Hinojosa, J. A., Albert, J., López-Martín, S., and Carretié, L. (2014). Temporospatial analysis of explicit and implicit processing of negative content during Word comprehension. Brain Cogn. 87, 109-121. doi: 10.1016/j.bandc.2014.03.008

Hinojosa, J. A., Carretié, L., Valcárcel, M. A., Méndez-Bértolo, C., and Pozo, M. A. (2009). Electrophysiological differences in the processing of affective information in words and pictures. Cogn. Affect. Behav. Neurosci. 9, 173-189. doi: 10.3758/CABN.9.2.173

Hinojosa, J. A., Méndez-Bértolo, C., Carretié, L., and Pozo, M. A. (2010a). Emotion modulates language production during covert picture naming. Neuropsychologia 48, 1725-1734. doi: 10.1016/j.neuropsychologia.2010.02.020

Hinojosa, J. A., Méndez-Bértolo, C., and Pozo, M. A. (2010b). Looking at emotional words is not the same as reading emotional words: behavioral and neural correlates. Psychophysiology 47, 748-757.

Hodsoll, S., Viding, E., and Lavie, N. (2011). Attentional capture by irrelevant emotional distractor faces. Emotion 11, 346-353. doi: 10.1037/a0022771

Hofmann, M. J., Kuchinke, L., Tamm, S., Vo, M. L. H., and Jacobs, A. M. (2009). Affective processing within 1/10th of a second: high arousal is necessary for early facilitative processing of negative but not positive words. Cogn. Affect. Behav. Neurosci. 9, 389-397. doi: 10.3758/9.4.389

Holmes, A., Kiss, M., and Eimer, M. (2006). Attention modulates the processing of emotional expression triggered by foveal faces. Neurosci. Lett. 394, 48-52. doi: 10.1016/j.neulet.2005.10.002

Ito, T. A., and Cacioppo, J. T. (2005). Variations on a human universal: individual differences in positivity offset and negativity bias. Cogn. Emot. 19, 1-26. doi: 10.1080/02699930441000120

Kanske, P., and Kotz, S. A. (2007). Concreteness in emotional words: ERP evidence from a hemifield study. Brain Res. 1148, 138-148. doi: 10.1016/j.brainres.2007.02.044

Kastner, S., De Weerd, P., Desimone, R., and Ungerleider, L. G. (1998). Mechanisms of directed attention in the human extrastriate cortex as revealed by functional MRI. Science 282, 108-111. doi: 10.1126/science.282.5386.108

Kawasaki, H., Kaufman, O., Damasio, H., Damasio, A. R., Granner, M., Bakken, H., et al. (2001). Single-neuron responses to emotional visual stimuli in human ventral prefrontal cortex. Nat. Neurosci. 4, 15-16. doi: 10.1038/82850

Keil, A., and Ihssen, N. (2004). Identification facilitation for emotionally arousing verbs during the attentional blink. Emotion 4, 23-35. doi: 10.1037/15283542.4.1.23 
Keuper, K., Zwitserlood, P., Rehbein, M. A., Eden, A. S., Laeger, I., Junghöfer, M., et al. (2013). Early prefrontal brain responses to the hedonic quality of emotional words-A simultaneous EEG and MEG study. PLoS ONE 8:e70788. doi: 10.1371/journal.pone.0070788

Kissler, J., and Herbert, C. (2013). Emotion, Etmnooi, or Emitoon?-Faster lexical access to emotional than to neutral words during reading. Biol. Psychol. 92, 464-479. doi: 10.1016/j.biopsycho.2012.09.004

Kissler, J., Herbert, C., Peyk, P., and Junghofer, M. (2007). Buzzwords: early cortical responses to emotional words during reading. Psychol. Sci. 18, 475-480. doi: 10.1111/j.1467-9280.2007.01924.x

Kissler, J., Herbert, C., Winkler, I., and Junghofer, M. (2009). Emotion and attention in visual word processing: an ERP study. Biol. Psychol. 80, 75-83. doi 10.1016/j.biopsycho.2008.03.004

Kissler, J., and Koessler, S. (2011). Emotionally positive stimuli facilitate lexical decisions-An ERP study. Biol. Psychol. 86, 254-264. doi: 10.1016/j.biopsycho.2010.12.006

Kuchinke, L., and Lux, V. (2012). Caffeine improves left hemisphere processing of positive words. PLoS ONE 7:e48487. doi: 10.1371/journal.pone.0048487

Lewis, P. A., Critchley, H. D., Rotshtein, P., and Dolan, R. J. (2007). Neural correlates of processing valence and arousal in affective words. Cereb. Cortex 17, 742-748. doi: $10.1093 /$ cercor/bhk024

Luck, S. J. (2005). An Introduction to the Event-Related Potential Technique. Cambridge: The MIT Press.

Luck, S. J., Fan, S., and Hillyard, S. A. (1993). Attention-related modulation of sensory-evoked brain activity in a visual search task. J. Cogn. Neurosci. 5, 188-195. doi: 10.1162/jocn.1993.5.2.188

MacLeod, C., Mathews, A., and Tata, P. (1986). Attentional bias in emotional disorders. J. Abnorm. Psychol. 95, 15-20. doi: 10.1037/0021-843X.95.1.15

MacNamara, A., and Hajcak, H. (2009). Anxiety and spatial attention moderate the electrocortical response to aversive pictures. Neuropsychologia 47, 2975-2980. doi: 10.1016/j.neuropsychologia.2009.06.026

MacNamara, A., Kappenman, E. S., Black, S. R., Bress, J. N., and Hajcak, G. (2013) "Integrating behavioral and electrocortical measures of attentional bias towards threat," in Handbook of Selfregulatory Processes in Development, eds K. C. Barret N. A. Fox, G. A. Morgan, D. J. Fidler, and L. A. Daunhauer (New York: Psychology Press), 215-243.

McKenna, F. P., and Sharma, D. (1995). Intrusive cognitions: an investigation of the emotional Stroop task. J. Exp. Psychol. Learn. Mem. Cogn. 21, 1595-1607. doi: 10.1037/0278-7393.21.6.1595

Méndez-Bértolo, C., Pozo, M. A., and Hinojosa, J. A. (2011). Word frequency modulates the processing of emotional words: Convergent behavioral and electrophysiological data. Neurosci. Lett. 494, 250-254. doi: 10.1016/j.neulet.2011.03.026

Michel, C. M., and Murray, M. M. (2012). Towards the utilization of EEG as a brain imaging tool. Neuroimage 61,371-385. doi: 10.1016/j.neuroimage.2011.12.039

Mitchell, D. G., Nakic, M., Fridberg, D., Kamel, N., Pine, D. S., and Blair, R. J. (2007). The impact of processing load on emotion. Neuroimage 34, 1299-1309. doi: 10.1016/j.neuroimage.2006.10.012

Mogg, K., and Bradley, B. P. (1998). A cognitive-motivational analysis of anxiety. Behav. Brain Ther. 36, 809-848. doi: 10.1016/S0005-7967(98)00063-1

Mulert, C., Jäger, L., Schmitt, R., Bussfeld, P., Pogarell, O., Möller, H. J., et al. (2004). Integration of fMRI and simultaneous EEG: towards a comprehensive understanding of localization and time-course of brain activity in target detection. Neuroimage 22, 83-94. doi: 10.1016/j.neuroimage.2003.10.051

Natale, E., Marzi, C. A., Girelli, M., Pavone, E. F., and Pollmann, S. (2006). ERP and fMRI correlates of endogenous and exogenous focusing of visual-spatia attention. Eur. J. Neurosci. 23, 2511-2521. doi: 10.1111/j.1460-9568.2006.04756.x

Nichols, T. E., and Holmes, A. P. (2002). Nonparametric permutation tests for functional neuroimaging: a primer with examples. Hum. Brain Mapp. 15, 1-25. doi: $10.1002 / \mathrm{hbm} .1058$

Nitschke, J. B., Nelson, E. E., Rusch, B. D., Fox, A. S., Oakes, T. R., and Davidson, R. J. (2004). Orbitofrontal cortex tracks positive mood in mothers viewing pictures of their newborn infants. Neuroimage 21, 583-592. doi: 10.1016/j.neuroimage.2003.10.005

O’Doherty, J., Rolls, E. T., Francis, S., Bowtell, R., and McGlone, F. (2001). Representation of pleasant and aversive taste in the human brain. J. Neurophysiol. 85, 1315-1321.

Oldfield, R. C. (1971). The assessment and analysis of handedness: the Edinburgh inventory. Neuropsychologia 9, 97-113. doi: 10.1016/0028-3932(71)90067-4
Pandya, D. N., and Yeterian, E. H. (1996). Comparison of prefrontal architecture and connections. Philos. Trans. Soc. Lond. B Biol. Sci. 29, 1423-1432. doi: 10.1098/rstb.1996.0127

Pascual-Marqui, R. D. (2007). Discrete, 3D Distributed, Linear Imaging Methods of Electric Neuronal Activity. Part 1: Exact, Zero Error Localization. Available at: http://arxiv.org/pdf/0710.3341 (accessed October 17, 2007).

Pascual-Marqui, R. D., Lehmann, D., Koukkou, M., Kochi, K., Anderer, P., Saletu, B., et al. (2011). Assessing interactions in the brain with exact low-resolution electromagnetic tomography. Philos. Trans. A Math. Phys. Eng. Sci. 369, 37683784. doi: 10.1098/rsta.2011.0081

Pérez-Edgar, K., and Fox, N. A. (2003). Individual differences in children's performance during an emotional Stroop task: a behavioral and electrophysiological study. Brain Cogn. 52, 33-51. doi: 10.1016/S0278-2626(03)00007-1

Pessoa, L., and Ungerleider, L. G. (2004). Neuroimaging studies of attention and the processing of emotion-laden stimuli. Prog. Brain Res. 144, 171-182. doi: 10.1016/S0079-6123(03)14412-3

Posner, M. I., Rueda, M. R., and Kanske, P. (2007). "Probing the mechanism of attention," in The handbook of psychophysiology, 3rd Edn, eds J. T. Cacioppo, J. G. Tassinary, and G. G. Berntson (Cambridge: Cambridge University Press), 410-432. doi: 10.1017/CBO9780511546396.018

Pourtois, G., Delplanque, S., Michel, C., and Vuilleumier, P. (2008). Beyond conventional event-related brain potential (ERP): exploring the time-course of visual emotion processing using topographic and principal component analyses. Brain Topogr. 20, 265-277. doi: 10.1007/s10548-008-0053-6

Pourtois, G., Grandjean, D., Sander, D., and Vuilleumier, P. (2004). Electrophysiological correlates of rapid spatial orientating towards fearful faces. Cereb. Cortex 14, 619-633. doi: 10.1093/cercor/bhh023

Pourtois, G., Schettino, A., and Vulleumier, P. (2013). Brain mechanisms for emotional influences on perception and attention: what is magic and what is not. Biol. Psychol. 92, 492-512. doi: 10.1016/j.biopsycho.2012.02.007

Pourtois, G., Spinelli, L., Seeck, M., and Vuilleumier, P. (2010). Temporal precedence of emotion over attention modulations in the lateral amygdala: intracranial evidence from a patient with temporal lobe epilepsy. Cogn. Affect. Behav. Neurosci 10, 83-93. doi: 10.3758/CABN.10.1.83

Pratto, F., and John, O. P. (1991). Automatic vigilance: the attention-grabbing power of negative social information. J. Pers. Soc. Psychol. 61, 380-391. doi: 10.1037/0022-3514.61.3.380

Rampone, G., Makin, A. D., and Bertamini, M. (2014). Electrophysiological analysis of the affective congruency between pattern regularity and word valence. Neuropsychologia 58, 107-117. doi: 10.1016/j.neuropsychologia.2014. 04.005

Rellecke, J., Palazova, M., Sommer, W., and Schacht, A. (2011). On the automaticity of emotion processing in words and faces: event-related brain potentials evidence from a superficial task. Brain Cogn. 77, 23-32. doi: 10.1016/j.bandc.2011.07.001

Rolls, E. T. (2000). The orbitofrontal cortex. Cereb. Cortex 10, 284-294. doi: 10.1093/cercor/10.3.284

Salemink, E., van den Hout, M. A., and Kindt, M. (2007). Selective attention and threat. Quick orienting versus slow disengagement and two versions of the dot probe task. Behav. Res. Ther. 45, 607-615. doi: 10.1016/j.brat.2006. 04.004

Schacht, A., Adler, N., Chen, P., Guo, T., and Sommer, W. (2012). Association with positive outcome induces early effects in event-related brain potentials. Biol. Psychol. 89, 130-136. doi: 10.1016/j.biopsycho.2011.10.001

Schacht, A., and Sommer, W. (2009a). Time course and task dependence of emotion effects in word processing. Cogn. Affect. Behav. Neurosci. 9, 28-43. doi 10.3758/CABN.9.1.28

Schacht, A., and Sommer, W. (2009b). Emotions in word and face processing: early and late cortical responses. Brain Cogn. 69, 538-550. doi: 10.1016/j.bandc.2008.11.005

Schimmack, U., and Derryberry, D. (2005). Attentional interference effects of emotional pictures: threat, negativity, or arousal? Emotion 5, 55-66. doi: 10.1037/1528-3542.5.1.55

Schlochtermeier, L., Kuchinke, L., Pehrs, C., Urton, K., Kappelhoff, H., and Jacobs, A. M. (2013). Processing emotional pictures and words: effects of stimulus complexity. PLoS ONE 8:e55619. doi: 10.1371/journal.pone.0055619.

Scott, G. C., O’Donnell, P. J., Leuthold, H., and Sereno, S. C. (2009). Early emotion word processing: evidence from event-related potentials. Biol. Psychol. 80, 95-104. doi: 10.1016/j.biopsycho.2008.03.010 
Serences, J. T., and Yantis, S. (2007). Spatially selective representations of voluntary and stimulus-driven attentional prioriry in human occipital, parietal, and frontal cortex. Cereb. Cortex 17, 284-293. doi: 10.1093/cercor/bhj146

Skrandies, W. (1998). Evoked potential correlates of semantic meaning-A brain mapping study. Brain Res. Cogn. Brain Res. 6, 173-183. doi: 10.1016/S09266410(97)00033-5

Sokolov, E. N. (1963). Perception and the Conditions Reflex. New York: Pergamon Press.

Stolarova, M., Keil, A., and Moratti, S. (2006). Modulation of the C1 visual eventrelated component by conditioned stimuli: evidence for sensory plasticity in early affective perception. Cereb. Cortex 16, 876-887. doi: 10.1093/cercor/bhj031

Stormark, K. M., Nordby, H., and Hugdahl, K. (1995). Attentional shifts to emotionally charged cues: behavioural and ERP data. Cogn. Emot. 9, 507-523. doi: 10.1080/02699939508408978

Thomas, S. J., Johnstone, S. J., and Gonsalvez, C. J. (2007). Event-related potentials during an emotional Stroop task. Int. J. Psychophysiol. 63, 221-231. doi 10.1016/j.ijpsycho.2006.10.002

Trauer, S. M., Andersen, S. K., Kotz, S. A., and Müller, M. M. (2012). Capture of lexical but not visual resources by task-irrelevant emotional words: a combined ERP and steady-state visual evoked potential study. Neuroimage 60, 130-138. doi: 10.1016/j.neuroimage.2011.12.016

Vitacco, D., Brandeis, D., Pascual-Marqui, R., and Martin, E. (2002). Correspondence of event-related potential tomography and functional magnetic resonance imaging during language processing. Hum. Brain Mapp. 17, 4-12. doi: 10.1002/hbm.10038

Vogel, E. K., and Luck, S. J. (2000). The visual N1 component as an index of a discrimination process. Psychophysiology 37, 190-203. doi: 10.1111/1469-8986.37 20190

Vuilleumier, P. (2005). How brain beware: neural mechanisms of emotional attention. Trends Cogn. Sci. 9, 585-594. doi: 10.1016/j.tics.2005.10.011
Vuilleumier, P., Armony, J. L., Driver, J., and Dolan, R. J. (2001). Effects of attention and emotion on face processing in the human brain: an event-related fMRI study. Neuron 30, 829-841. doi: 10.1016/S0896-6273(01)00328-2

Yantis, S. (2000). "Goal directed and stimulus driven determinants of attentional control," in Control of Cognitive Processes: Attention and Performance, XVIII Edn, eds S. Monsell and J. Driver (Cambridge: MIT Press), 73-103.

Zajonc, R. B. (1980). Feeling and thinking: preferences need no inferences. Am. Psychol. 35, 151-175. doi: 10.1037/0003-066X.35.2.151

Zhang, W., Li, H., Chen, J., Chen, N., Liu, X., Wang, D., et al. (2014). Posterior P1 and early frontal negativity reflect developmental changes in attentional distraction during adolescence. Brain Cogn. 87, 30-38. doi: 10.1016/j.bandc.2014.02.011

Conflict of Interest Statement: The authors declare that the research was conducted in the absence of any commercial or financial relationships that could be construed as a potential conflict of interest.

Received: 25 September 2014; accepted: 07 January 2015; published online: 26 January 2015.

Citation: Hinojosa JA, Mercado F, Albert J, Barjola P, Peláez I, Villalba-García C and Carretié L (2015) Neural correlates of an early attentional capture by positive distractor words. Front. Psychol. 6:24. doi: 10.3389/fpsyg.2015.00024

This article was submitted to Language Sciences, a section of the journal Frontiers in Psychology.

Copyright (ㄷ 2015 Hinojosa, Mercado, Albert, Barjola, Peláez, Villalba-García and Carretié. This is an open-access article distributed under the terms of the Creative Commons Attribution License (CC BY). The use, distribution or reproduction in other forums is permitted, provided the original author(s) or licensor are credited and that the original publication in this journal is cited, in accordance with accepted academic practice. No use, distribution or reproduction is permitted which does not comply with these terms. 